\section{$\underset{\substack{\text { hommes } \\ \text { \& migrations }}}{ }$}

\section{Hommes \& migrations}

Revue française de référence sur les dynamiques

migratoires

$1321 \mid 2018$

Les mots de l'exil dans l'Europe du XIXe siècle

\title{
Fawaz Hussain, Le rêveur des bords du Tigre
}

Paris, Les Escales 2017, 172 pages, 16,90€.

\section{Mustapha Harzoune}

\section{(2) OpenEdition}

1 Journals

\section{Édition électronique}

URL : http://journals.openedition.org/hommesmigrations/4574

DOI : ERREUR PDO dans /localdata/www-bin/Core/Core/Db/Db.class.php L.34 : SQLSTATE[HY000]

[2006] MySQL server has gone away

ISSN : 2262-3353

Éditeur

Musée national de l'histoire de l'immigration

Édition imprimée

Date de publication : 1 avril 2018

Pagination : 179-180

ISBN : 978-2-919040-41-4

ISSN : $1142-852 X$

Référence électronique

Mustapha Harzoune, "Fawaz Hussain, Le rêveur des bords du Tigre», Hommes \& migrations [En ligne],

1321 | 2018, mis en ligne le 01 avril 2018, consulté le 08 janvier 2021. URL : http://

journals.openedition.org/hommesmigrations/4574 ; DOl : https://doi.org/10.4000/

hommesmigrations.4574 


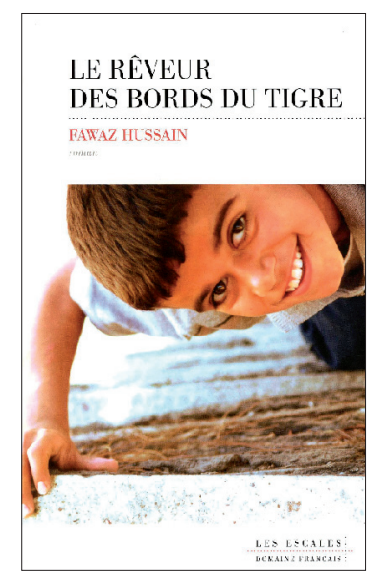

\section{Fawaz Hussain}

Le rêveur

des bords du Tigre

Paris, Les Escales 2017,172

pages, $16,90 €$

En mêlant le réel et le fantastique, la fable et le tragique, Fawaz Hussain affirme ici sa singularité d'écrivain. Dans Le rêveur des bords du Tigre, un moineau tient lieu d'éveilleur et de mémoire. Une ogresse se goinfre de chair d'enfants. Un gavroche de Diyarbakir refuse de grandir. Morts et vivants se confondent. Les âmes se transforment en papillons blancs. « Le pays des droits de l'homme et de la gastronomie " accorde sa protection à un cuistot menacé pour un poulet rôti au sumac. Le narrateur qui, en douce, sirote son raki sur les berges du Tigre "aura toujours la tête dans les nuages".

Après vingt-cing ans de solitude parisienne, Farzand décide de rentrer. Si l'exil ne fut pas " une malédiction ", ses espérances sont «en débandade ». Comble de malheur, ce retour vers l'Ithaque mésopotamienne a tout d'un impossible retour vers "la topographie de la folie». Au drame kurde s'ajoute le " crématorium » des printemps arabes. Le tout sous le regard indifférent de l'Occident"l'âme aseptisée des Européens [et] des Américains".

En chemin vers le "royaume de l'enfance ", Farzand s'arrête à Diyarbakir. Au détour de ses pérégrinations, reviennent les souvenirs d'une existence. Plus proche de Cioran (" tout n'est pas perdu tant qu'on est mécontent de soi ») et d'un Roumi que de la "camaraderie" des militants de l'" Organisation », le FrancoKurde découvre que Diyarbakir « n'a plus rien d'une capitale kurde ": "comme l'armée turque, les élus kurdes tenant la mairie jouaient leur rôle dans cette tragédie à ciel ouvert. Le vrai bourreau et la fausse victime visaient à l'éradication des spécificités kurdes et à l'assimilation complète du peuple. " Le turc triomphe; elle n'est plus la «langue de l'occupant». Ses locuteurs - puissant, intellectuel ou employé - se gobergent du kurde, "la langue des paysans et des analphabètes". Seul Mirza, un enfant obligé de vendre des pépins de pastèque, s'exprime dans la 


\section{LIVRES}

langue ancestrale. La ville tremble sous la poigne de Kara Yildiz - satrape de l' "Organisation", turcophone, téléphage, ogresse gloutonne aux excrétions intempestives. Fawaz Hussain dénonce l' "hystérie politique", le contrôle social et la terreur exercés par l' "Organisation" et Serok, son chef emprisonné. Les Kurdes seraient-ils condamnés à être les "valets des valets, [les] esclaves des esclaves "?

Face à la turquisation des bouches et des esprits, l'heure n'est pas au métissage c'est le moins que l'on puisse dire icimais à pointer les menaces qui pèsent sur des populations, sur une langue et une culture. Farzand se souvient des mots de sa grand-mère- " Oh! Tirko, oh! traître de Tirko! » - et de la frontière qui, du côté d'Amoudé, a fracturé l'espace. Tracée par la France - « maudits soient ceux qui ont fait cette frontière " - entre la jeune République turque et le nord de la Syrie, elle a séparé les familles kurdes
" sous le regard et la violence des gendarmes et policiers des deux pays, à la place du sang, la haine du Kurde et la corruption coulaient dans leurs veines".

Ulysse/Farzand ne reconnait rien ni personne et personne ne remet celui qui s'en revient. Sans reconnaissance pas de renaissance. Tout espoir serait-il mort? Mirza et sa mère seront-ils le Télémaque et la Pénélope de ce kurde au passeport français ? Le rêveur des bords du Tigre est un conte à pleurer jusqu'au bout de la nuit mésopotamienne. Pourtant, toute clarté n'a pas disparu. Les effluves d'un parfum aux roses d'Ispahan restent la "preuve irréfutable que la vie pouvait rester émouvante ». Un enfant peut " restituer la beauté des choses » et ressusciter l'espoir. À la question de savoir «à quoi rêvent les Kurdes? », Farzand repasse les plats de la libération du Kurdistan. « Non, répond le moineau, à la paix» !

Mustapha Harzoune 